\title{
BMJ Global Health Equity of geographical access to public health facilities in Nepal
}

\author{
Wen-Rui Cao, ${ }^{1}$ Prabin Shakya, ${ }^{2}$ Biraj Karmacharya, ${ }^{2}$ Dong Roman Xu, ${ }^{3,4}$ \\ Yuan-Tao Hao, ${ }^{1,5}$ Ying-Si Lai (i) ${ }^{1,5}$
}

To cite: Cao W-R, Shakya P, Karmacharya B, et al. Equity of geographical access to public health facilities in Nepal. BMJ Global Health 2021;6:e006786. doi:10.1136/ bmjgh-2021-006786

Handling editor Sanni Yaya

- Additional supplemental material is published online only. To view, please visit the journal online (http://dx.doi.org/10. 1136/bmjgh-2021-006786).

Received 1 July 2021 Accepted 3 October 2021

Check for updates

(c) Author(s) (or their employer(s)) 2021. Re-use permitted under CC BY-NC. No commercial re-use. See rights and permissions. Published by BMJ

${ }^{1}$ Department of Medical Statistics, School of Public Health, Sun Yat-Sen University, Guangzhou, Guangdong, China ${ }^{2}$ Departments of Public Health and Community Programs, Kathmandu University School of Medical Sciences, Dhulikhel, Nepal

${ }^{3}$ ACACIA Labs, SMU Institute for Global Health (SIGHT) and Dermatology Hospital, Southern Medical University, Guangzhou, Guangdong, China

${ }^{4}$ Center for WHO Studies and Department of Health Management, School of Health Management of Southern Medical University, Guangzhou, Guangdong, China

${ }^{5}$ Sun Yat-Sen Global Health Institute, Sun Yat-Sen University, Guangzhou, Guangdong, China

Correspondence to

Dr Ying-Si Lai;

laiys3@mail.sysu.edu.cn

\section{ABSTRACT}

Introduction Geographical accessibility is important against health equity, particularly for less developed countries as Nepal. It is important to identify the disparities in geographical accessibility to the three levels of public health facilities across Nepal, which has not been available.

Methods Based on the up-to-date dataset of Nepal formal public health facilities in 2021, we measured the geographical accessibility by calculating the travel time to the nearest public health facility of three levels (ie, primary, secondary and tertiary) across Nepal at $1 \times 1 \mathrm{~km}^{2}$ resolution under two travel modes: walking and motorised. Gini and Theil $L$ index were used to assess the inequality. Potential locations of new facilities were identified for best improvement of geographical efficiency or equality. Results Both geographical accessibility and its equality were better under the motorised mode compared with the walking mode. If motorised transportation is available to everyone, the population coverage within 5 min to any public health facilities would be improved by $62.13 \%$. The population-weighted average travel time was 17.91 min, $39.88 \mathrm{~min}$ and $69.23 \mathrm{~min}$ and the Gini coefficients $0.03,0.18$ and 0.42 to the nearest primary, secondary and tertiary facilities, respectively, under motorised mode. For primary facilities, low accessibility was found in the northern mountain belt; for secondary facilities, the accessibility decreased with increased distance from the district centres; and for tertiary facilities, low accessibility was found in most areas except the developed areas like zonal centres. The potential locations of new facilities differed for the three levels of facilities. Besides, the majority of inequalities of geographical accessibility were from within-province.

Conclusion The high-resolution geographical accessibility maps and the assessment of inequality provide valuable information for health resource allocation and healthrelated planning in Nepal.

\section{INTRODUCTION}

Health equity receives worldwide attention, the improvement of which is one of the main goals of health development in most countries. ${ }^{1}$ Nepal is one of the least developed countries, with fragmented health system, insufficient health resources and poor sanitation. ${ }^{2-4}$ Public health services initiated by the

\section{Key questions}

What is already known?

- Most previous studies in Nepal summarised the average travel time of different populations in certain regions/the whole country based on cross-sectional surveys on sampled residents, and did not provide enough information on geographical accessibility of each residential settlement to health facility across the country.

- One study produced global maps of travel time to healthcare facilities at high resolution, but the accessibility may be underestimated as small health posts/centres providing primary healthcare services might be omitted.

- No study has assessed the geographical accessibility to different levels (ie, primary, secondary and tertiary) of public health facilities across Nepal.

\section{What are the new findings?}

- High-resolution maps showed wide variations in the distribution of geographical accessibility of different levels of public health facilities across the country.

- In 2021, most people (92.54\%) could access to public health facilities within 15 min with the motorised travel mode, and most people (94.63\%) had accessibility within 60 min with walking mode. If motorised transportation is available to everyone, the population coverage within 5 min to any public health facilities would be improved by $62.13 \%$, compared with that with walking mode.

- Only less than two-thirds and around one-third of population had good geographical accessibility $(<30$ $\mathrm{min}$ ) to secondary and tertiary facilities, respectively, with the motorised mode.

- The geographical accessibility and its equality decreased with the increase of levels of facilities, and the the majority of inequalities were from within-province.

- Potential locations of new facilities for the three levels were provided, to best improve the efficiency or equality of geographical accessibility.

government are arguably the backbone of the entire health system. ${ }^{2}$ Although the country has made notable progress in health outcomes over the past two decades, ${ }^{5}$ inequity in access to healthcare is still significant. ${ }^{67}$ Particularly, 


\section{Key questions}

What do the new findings imply?

- The high-resolution maps identify vulnerable areas for additional public health facilities to optimise geographical accessibility of public health services at three levels in Nepal. Accessibility with motorised mode better than that with walking mode highlights the importance of a more efficiency public transport system and better transportation network in Nepal. Low geographical accessibility and high disparities of higher level health facilities urge the government to advance the hierarchical healthcare system.

- Methods described in the study could be adopted to similar contexts in other low-income and middle-income countries.

one of the major barriers were poor geographical accessibility of many people, according to the Nepal Health Sector Strategy 2015-2020. ${ }^{8}$ Indeed, studies have shown that the utilisation of healthcare is closely related to the physical accessibility to medical services. ${ }^{9} 10$ Therefore, it is important to understand the different geographical accessibilities to public health facilities across the country, where areas with poor geographical accessibility can be identified, providing useful information for policy makers to allocate health resources.

To our knowledge, studies on accessibility to health resources in Nepal are few, most of which are based on cross-sectional surveys on sampled residents. ${ }^{6}{ }^{11}$ According to the Nepal Living Standards Survey 20102011 , only $61.8 \%$ of households in Nepal can reach the nearest health posts within $30 \mathrm{~min}$, with significant urban and rural differences. ${ }^{11}$ However, these studies did not provide enough information on geographical accessibility of each residential settlement to public health facility across the country. Recently, Weiss et al produced global maps of travel time to healthcare facilities at high resolution, where the geographical accessibility to facilities in Nepal are shown. ${ }^{12}$ Geographical information of health facilities were extracted from Google Maps, OpenStreetMap and other published sources, where small health posts/centres may be omitted, thus might underestimate the accessibility.

In addition, different levels of health facilities provide different health services. ${ }^{13}$ Nepal public health facilities were mainly categorised into three levels-primary, secondary and tertiary. ${ }^{13}$ Primary level facilities provided promotive and preventive services, in addition to basic curative services; secondary level facilities were the referral points of the primary ones and provided further inpatient, outpatient, emergency and comprehensive emergency obstetric and neonatal care services; and tertiary level facilities were the referral points of the secondary ones, providing support to lower level facilities, as well as offering professional training and conducting scientific research. ${ }^{13}$ The majority of the time, the primary or the secondary healthcare services are able to meet the health need of people, while when people have severe injuries or diseases, higher level healthcare services are required. Simply focusing on overall geographical accessibility analysis may not provide enough information to optimise the allocation of healthcare resources at different levels. Studies have been undertaken to assess the different accessibilities to different levels of healthcare. A survey done by van Loenhout $e t$ al across Nepal showed that patients required surgical care spent more time to reach tertiary health facilities than that to secondary ones. ${ }^{14}$ Cheng et al examined the spatial accessibility to multiple levels of hospital care services for older adults in Nanjing, China, and found that higher level hospitals located more unevenly than lower level ones. ${ }^{15}$ To our knowledge, there has not been study to assess the geographical accessibility to different levels of public healthcare services across Nepal.

In this study, using the up-to-date dataset of Nepal formal public health facilities in 2021, we conducted spatial analyses to measure the geographical accessibility to different levels of public health facilities at high-spatial resolution; based on which, we further assessed the equality of geographical accessibility and provided potential locations where new public health facilities could be built to improve efficiency or equality of geographical accessibility. Results of the study can provide useful reference for evidence-based health planning and resource allocation decisions.

\section{METHODS \\ Study area}

Nepal is an inland country in South Asia, located in the southern part of the Himalayas, bordering on China and India. It occupies an area of $147000 \mathrm{~km}^{2}$, with coordinates $26^{\circ} 22^{\prime}-30^{\circ} 27^{\prime}$ north latitude and $80^{\circ} 4^{\prime}-88^{\circ} 12^{\prime}$ east longitude. After the new constitution in 2015, the country has been reclassified into seven provinces and 77 districts, with Kathmandu the capital (online supplemental figure S1a). ${ }^{16}$ The elevation is generally low in the south and high in the north, ranged from around $60 \mathrm{~m}$ to over $8600 \mathrm{~m}$ (online supplemental figure S1b). The Himalayas part in the north and the terai lowland in the south accounts for $15 \%$ and $17 \%$ of the total area, respectively, while the central hill region coverages $68 \%$ of the total. The population in 2020 was approximate to 29.14 million, ${ }^{17}$ the majority of which live in terai and the hill areas (online supplemental figure S1c). ${ }^{18}$ The socioeconomic conditions across the country vary widely. ${ }^{19}$

\section{Data sources}

We obtained the latest inventory list of Nepal public health facilities registered up to 22 May 2021 from the dataset of Nepal Health Facility Registry. ${ }^{20}$ Collected by the Ministry of Health and Population, Nepal, the dataset provides unique identification code, name, type and service information of each registered health facility in Nepal and keeps updating. Around $38.30 \%$ of facilities were with location information in the dataset. For the coordinates of the remaining, we obtained them via the Health Infrastructure Information System 
in Nepal, ${ }^{21}$ Google maps, OpenStreetMap or other mapping service applications. According to the latest classification of public health facility in Nepal, ${ }^{13}$ all the public health facilities were regrouped into three levels: primary (ie, health post, primary health centre, primary hospital, urban health centre, basic health service centre, community health unit), secondary (ie, district hospital, district clinic) and tertiary (ie, central hospital, regional hospital, subregional hospital, zonal hospital) (online supplemental figure S1d). Up to 22 May 2021, there were 5425, 105 and 23 primary, secondary and tertiary facilities, respectively, making up a total of 5553 public health facilities. The density distribution of facilities was calculated based on the Kernel density estimation, the corresponding methods and results of which are shown in online supplemental appendix page 4 .

We obtained the population count data of 2020, which has been adjusted to match the corresponding official United Nations population estimates, from WorldPop at a spatial resolution of $1 \times 1 \mathrm{~km}^{2}{ }^{22}$ The friction surfaces in 2020 at $1 \times 1 \mathrm{~km}^{2}$ resolution were downloaded from the Malaria Atlas Project, ${ }^{23}$ which were further used for calculation of travel time between locations and health facilities. The links to all the data sources can be found in online supplemental table S1.

\section{Analysis}

Geographical accessibility

A regular $1 \times 1 \mathrm{~km}^{2}$ grid was overlaid to Nepal, resulted in 195574 pixels. The travel time to the nearest health facility was used to assess the geographical accessibility in each gridded pixel across Nepal. We calculated the travelling time considering two situations: the ideal travel situation (motorised mode) that people access facilities through optimal transport tools with the fastest speed, and the worst travel situation (walking mode) that people go to facilities mainly by foot, the lowest speed transport.

The friction surface 2020 produced by Weiss et al ${ }^{12}$ was overlaid to the study region, where the value of each pixel in the friction surface raster refers to the minutes required to travel per metre with the fastest traffic mode through the pixel. The least-cost-path algorithm developed by Dijkstra ${ }^{24}$ was used to calculate the travel time from each residential location to a public health facility accessible via the shortest journey. The algorithm tests all possible routes from the residential location to each facility and calculated the travel time based on the values of friction surface pixels covered by the routes. The minimum of travel time of all tested routes was adopted as the travel time of the residential location to the nearest health facility. Travel time with walking mode was calculated by replacing the friction pixels corresponding to road travel with a walking speed of $5 \mathrm{~km}$ per hour. ${ }^{12}$

Furthermore, we categorised the travel time into 7 ranges (minutes): $<5,5-15,15-30,30-60,60-90,90-120$, $>120$ and summarised the coverages of population belonging to each range. The average travel time of the country was calculated by summing up the travel time of each gridded pixel weighted by the corresponding population count and dividing the total population.

The methodology measuring geographical accessibility were validated by Nelson $e t a l^{25}$ and Weiss $e t a l,{ }^{12}$ by comparing the travel time calculated from the adopted methodology with the one obtained from the Google Maps API. The adopted methodology showed good performances. ${ }^{12} 25$ Furthermore, to evaluate whether the speed settings in the friction surfaces 2020 of Nepal, derived from OpenStreetMap, could result in robust and stable outcomes, we did sensitivity analysis by replacing the speed settings according to Nepal road standard speed $^{26} 27$ and Google Maps road speed, respectively (see online supplemental appendix for more details).

\section{Measures of inequality}

We adopted the Gini coefficient, the most widely used measure, ${ }^{28}$ to assess the inequality of geographical accessibility to the three levels of facilities, as well as to any public health facility. As travel time is a negative indicator for accessibility, it is not proper to be used directly. Instead, we chose a positive time-based indicator for accessibility, denoted as $x_{s}$, which indicates the extent of travel time affecting the spatial accessibility and is commonly used in gravity-based accessibility calculation. ${ }^{29}{ }^{30}$ It is expressed as a Gaussian impedance function with travel time, $x_{s}=e^{-t_{s}^{2} / \beta 30}$ where $t_{s}$ is the travel time between pixel $s$ to the nearest health facility, and $\beta$ the decay coefficient. The longer the travel time, the lower value of $x_{s}$ , suggesting less geographical accessibility. We assumed that travel time more than 120 min were geographical inaccessibility. ${ }^{31}$ By setting $x_{s}$ equal to 0.01 , a critical value of the Gaussian impedance function approaching zero suggested by Kwan, ${ }^{30}$ at the travel time of $120 \mathrm{~min}$, $\beta$ was assigned 3127 to the function. Furthermore, we calculated the Theil L index and its decompositions to assess the proportions of overall inequality derived from between-province and within-province. ${ }^{32}$ The formulas of Gini coefficient and Theil L index are shown in online supplemental appendix page 7 .

\section{Identification of locations for new facility}

We adopted Hulland $e t a l$ s approach to identify potential locations for new public facility. ${ }^{33}$ For each gridded pixel of the country, we recalculated the population-weighted average travel time of the country and the Gini coefficient in case a new health facility is located at the specific pixel. The reduction of average travel time/Gini coefficient in the pixel was calculated as the original average travel time/Gini coefficient minus the recalculation ones when a new facility was added there. Areas with the most reduction of the average travel time were identified as the best potential locations to improve the efficiency of geographical accessibility, while the ones with largest decrease of Gini coefficient were the best potential locations to improve the geographical equality.

All visualisations were performed with ArcGIS V.10.5, and all other analyses were done in R V.3.5.2. Particularly, 


\section{A motorized mode}
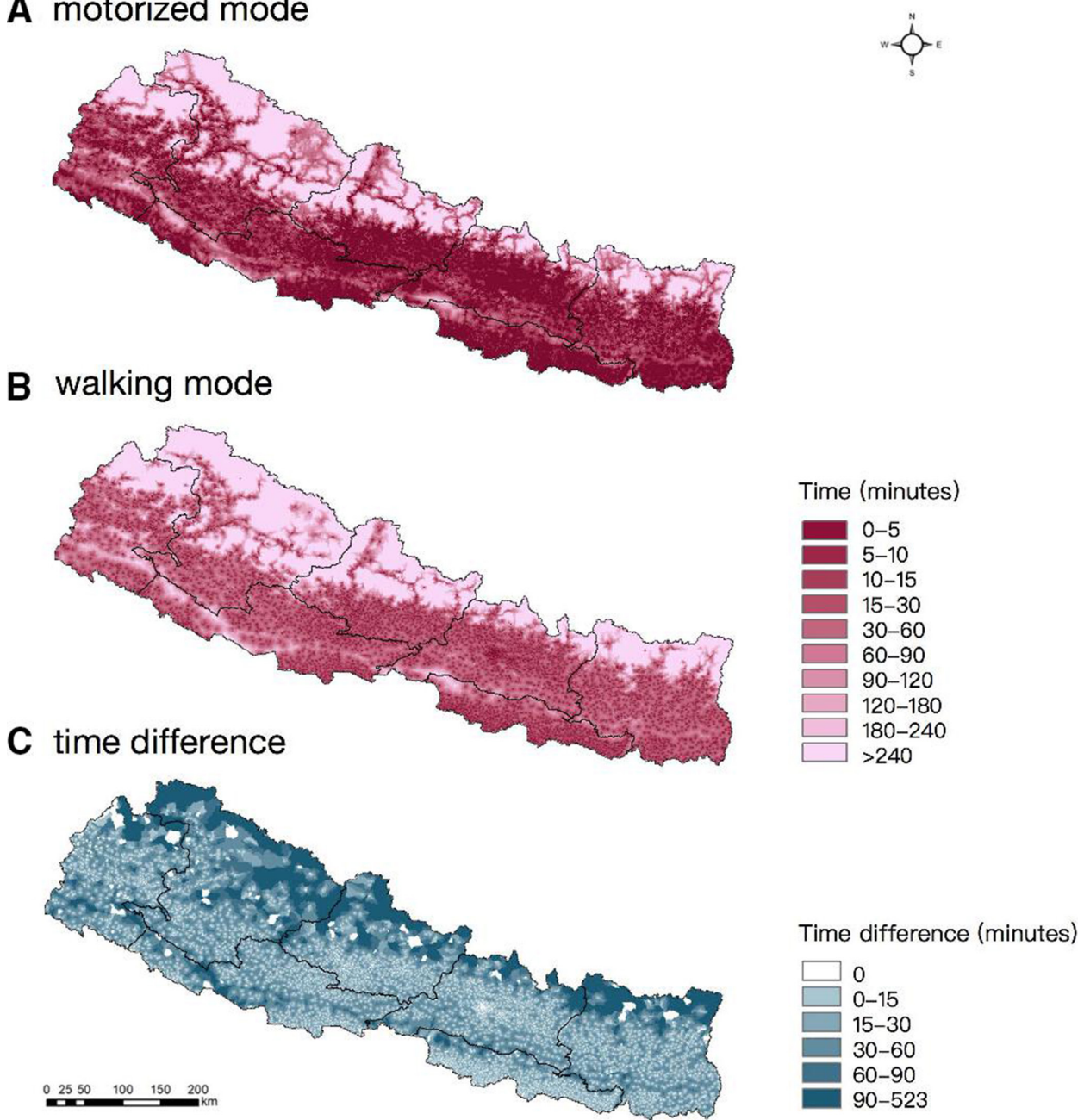

Figure 1 Geographical accessibility according to travel times to the nearest public health facilities with different travel modes. (A) the motorised mode; (B) the walking mode; (C) the difference between motorised and walking modes.

the gdistance package ${ }^{34}$ in $\mathrm{R}$ was used for travel time calculation.

\section{RESULTS}

\section{Geographical accessibility}

The results of sensitivity analysis showed that the population-weighted average travel time calculated based on the friction surface 2020 were quite close to results based on the other two road speed standards (online supplemental table S3), suggesting the outcomes were stable and reliable. The population-weighted average travel time to the nearest public health facility were 17.87 min and 33.97 min with the motorised and the walking modes, respectively (online supplemental table S4). The geographical accessibility was higher for the motorised mode than that for the walking one, particularly in those remote mountain areas in the northern part (figure 1). In addition, the geographical accessibility with both modes showed that the accessibility was high in the central and southern terai belt but low in the northern mountain areas (figure 1), indicating disparities of geographical accessibility across the country.
The population-weighted average travel time to the nearest primary, secondary and tertiary health facilities were $17.91 \mathrm{~min}, 39.88 \mathrm{~min}$ and $69.23 \mathrm{~min}$, respectively, with the motorised mode (online supplemental table S4). The geographical accessibility to the three levels of facilities distributed differently (figure 2): the accessibility to primary facilities was quite similar as that to overall public health facilities; while the accessibility to secondary ones was high in centres of most districts and gradually decreased with the increase of distance from the centres; high accessibility to tertiary ones was basically concentrated in Kathmandu and several zonal centres, and there was extremely low accessibility in the northern part of province No.1, No.4 and No.6.

Coverages of population with different degrees of accessibility is shown in table 1 and online supplemental table S5 and figure S3. Most people $(92.54 \%)$ could access to public health facilities within 15 min with the motorised mode, and most people (94.63\%) had accessibility within 60 min with walking mode. Still, a small proportion of people $(0.64 \%$ and $1.24 \%$ with motorised and walking modes, respectively) had extremely low accessibility ( $>2$ 


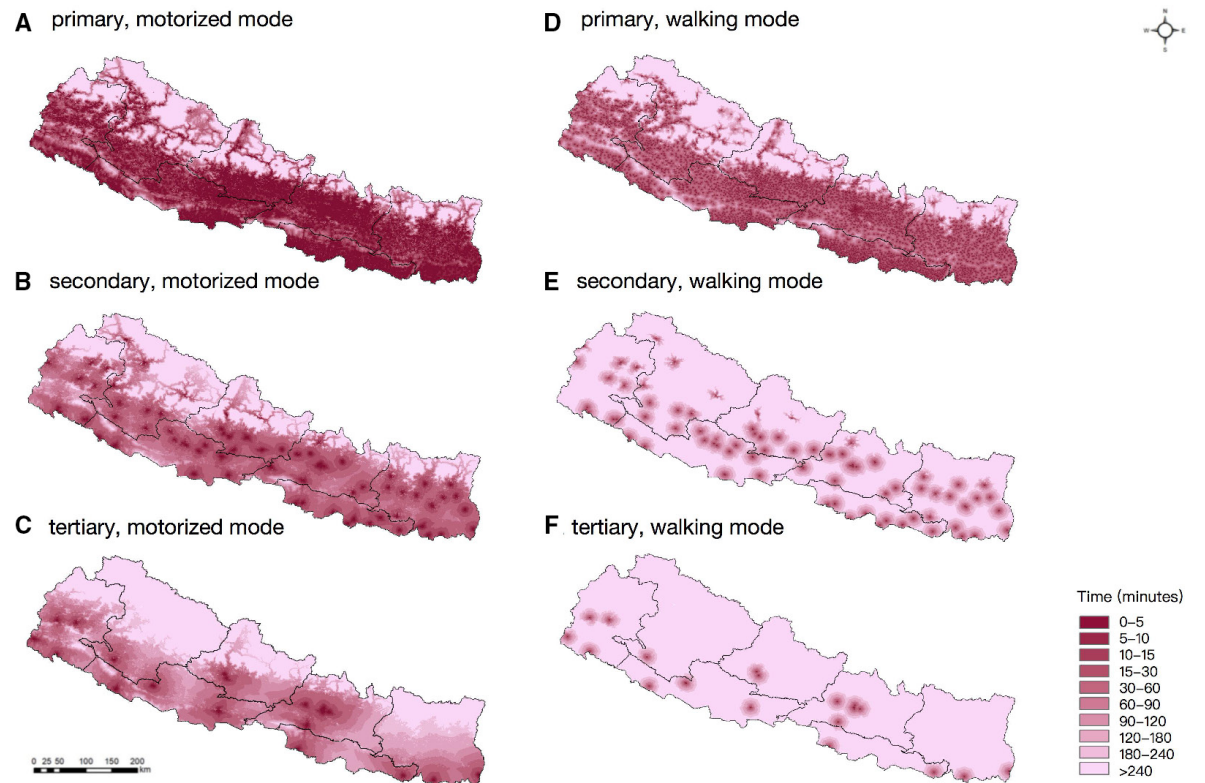

Figure 2 Geographical accessibility according to travel time to different levels of public health facilities. (A-C) to the nearest primary, secondary and tertiary health facilities, respectively, with the motorised mode; (D-F) to the nearest primary, secondary and tertiary health facilities, respectively, with the walking mode.

hours) to public health facilities. Furthermore, only less than two-thirds and around one-third of population had good accessibility $(<30 \mathrm{~min})$ to secondary and tertiary facilities, respectively, with the motorised mode. And the situation was worse, that less than $15 \%$ of population could reach secondary and tertiary facilities within 30 min with the walking mode. If motorised transportation is available to everyone, the population coverage within 5 min to any public health facilities can be improved by $62.13 \%$.

\section{Inequality}

As shown in table 2, equality of geographical accessibility in motorised mode was better than that in walking mode. Under the motorised mode, the geographical accessibility of any public health facilities, primary ones, and secondary ones was absolutely equal (with Gini $<0.2$ ), and that of tertiary ones was disparate (with $0.4<$ Gini $<0.5$ ). Under the walking mode, the geographical accessibility of any public health facilities and primary ones was absolutely equal (with Gini<0.2), while that of secondary and tertiary ones was extremely disparate (with Gini $>0.5$ ). Moreover, the inequalities of geographical accessibility mainly came from within-province, which accounted for over $90 \%$ of the overall inequalities for all three levels of facilities, under both travel modes.

\section{Potential locations for new facility}

The optimal locations of new public health facilities differ for the three levels with motorised mode (figure 3). For primary facilities, the potential locations for new facility could be located in the northern mountain belt areas (eg, areas in Humla district of province No.6 and Darchula district of province No.7), to best reduction of the average travel time. Whereas areas of the western terai belt (eg, areas in Rautahat district of province No.2, Dang district of province No.5 and Kanchanpur district of province No.7) could be chosen for new secondary facilities, and the eastern terai belt (eg, areas in most of province No.2) for new tertiary facilities, for both improvements

\begin{tabular}{|c|c|c|c|c|c|c|c|c|}
\hline \multirow[b]{2}{*}{ Travel mode } & \multirow[b]{2}{*}{ Facility level } & \multicolumn{7}{|c|}{ Travel time (min) } \\
\hline & & $<5$ & $5-15$ & $15-30$ & $30-60$ & $60-90$ & $90-120$ & $>120$ \\
\hline \multirow[t]{4}{*}{ Motorised mode } & Any & 78.47 & 14.07 & 3.51 & 2.22 & 0.51 & 0.22 & 0.64 \\
\hline & Primary & 78.15 & 14.34 & 3.55 & 2.23 & 0.51 & 0.22 & 0.64 \\
\hline & Secondary & 18.29 & 17.36 & 28.28 & 25.46 & 5.93 & 1.47 & 1.43 \\
\hline & Tertiary & 15.54 & 9.46 & 12.63 & 22.98 & 16.17 & 10.38 & 11.51 \\
\hline \multirow[t]{4}{*}{ Walking mode } & Any & 16.34 & 39.20 & 24.70 & 14.39 & 3.06 & 0.92 & 1.24 \\
\hline & Primary & 15.81 & 39.17 & 24.83 & 14.72 & 3.11 & 0.96 & 1.25 \\
\hline & Secondary & 1.35 & 6.50 & 6.64 & 10.56 & 7.85 & 8.44 & 58.64 \\
\hline & Tertiary & 0.75 & 4.46 & 5.92 & 7.54 & 4.56 & 3.14 & 73.63 \\
\hline
\end{tabular}


Table 2 Inequality of geographical accessibility and the decomposition

\begin{tabular}{|c|c|c|c|c|c|}
\hline Travel mode & Facility level & Measure & Overall & Within-province (\% of overall) & Between-province (\% of overall) \\
\hline \multirow[t]{8}{*}{ Motorised mode } & Any & Gini & 0.0293 & - & - \\
\hline & & Theil L & 0.0838 & $0.0832(99.26)$ & $0.0006(0.74)$ \\
\hline & Primary & Gini & 0.0294 & - & - \\
\hline & & Theil $L$ & 0.0839 & $0.0832(99.25)$ & $0.0007(0.75)$ \\
\hline & Secondary & Gini & 0.1809 & - & - \\
\hline & & Theil L & 0.2503 & 0.2374 (94.83) & $0.0129(5.17)$ \\
\hline & Tertiary & Gini & 0.4228 & . & . \\
\hline & & Theil L & 1.2292 & $1.1580(94.21)$ & 0.0711 (5.79) \\
\hline \multirow[t]{8}{*}{ Walking mode } & Any & Gini & 0.1266 & . & . \\
\hline & & Theil L & 0.1933 & 0.1864 (96.48) & 0.0068 (3.52) \\
\hline & Primary & Gini & 0.1283 & - & - \\
\hline & & Theil L & 0.1954 & $0.1883(96.34)$ & 0.0071 (3.66) \\
\hline & Secondary & Gini & 0.7598 & - & - \\
\hline & & Theil L & 7.9086 & 7.5147 (95.02) & 0.3938 (4.98) \\
\hline & Tertiary & Gini & 0.8257 & - & - \\
\hline & & Theil L & 13.2249 & 12.3026 (93.03) & $0.9223(6.97)$ \\
\hline
\end{tabular}

of the average geographical accessibility and equality of geographical accessibility. Maps for reductions of travel time and Gini coefficient for new public health facility placement with walking mode were shown in online supplemental figure $\mathrm{S} 4$.

\section{DISCUSSION}

In this study, we produced high-resolution maps of the geographical accessibility to different levels of public health facilities under two travel modes (ie, the walking and the motorised modes) in Nepal, identifying vulnerable areas with low geographical accessibility. The further inequality assessment suggested different inequality degrees of the three levels of facilities and that majority of the inequalities were attributed to differences within provinces. Moreover, potential locations were presented for best increase of the average geographical accessibility or for best improvement of the equality of geographical accessibility. The results can provide valuable information for scientific evidence-basic management of health resource planning and allocation in Nepal.

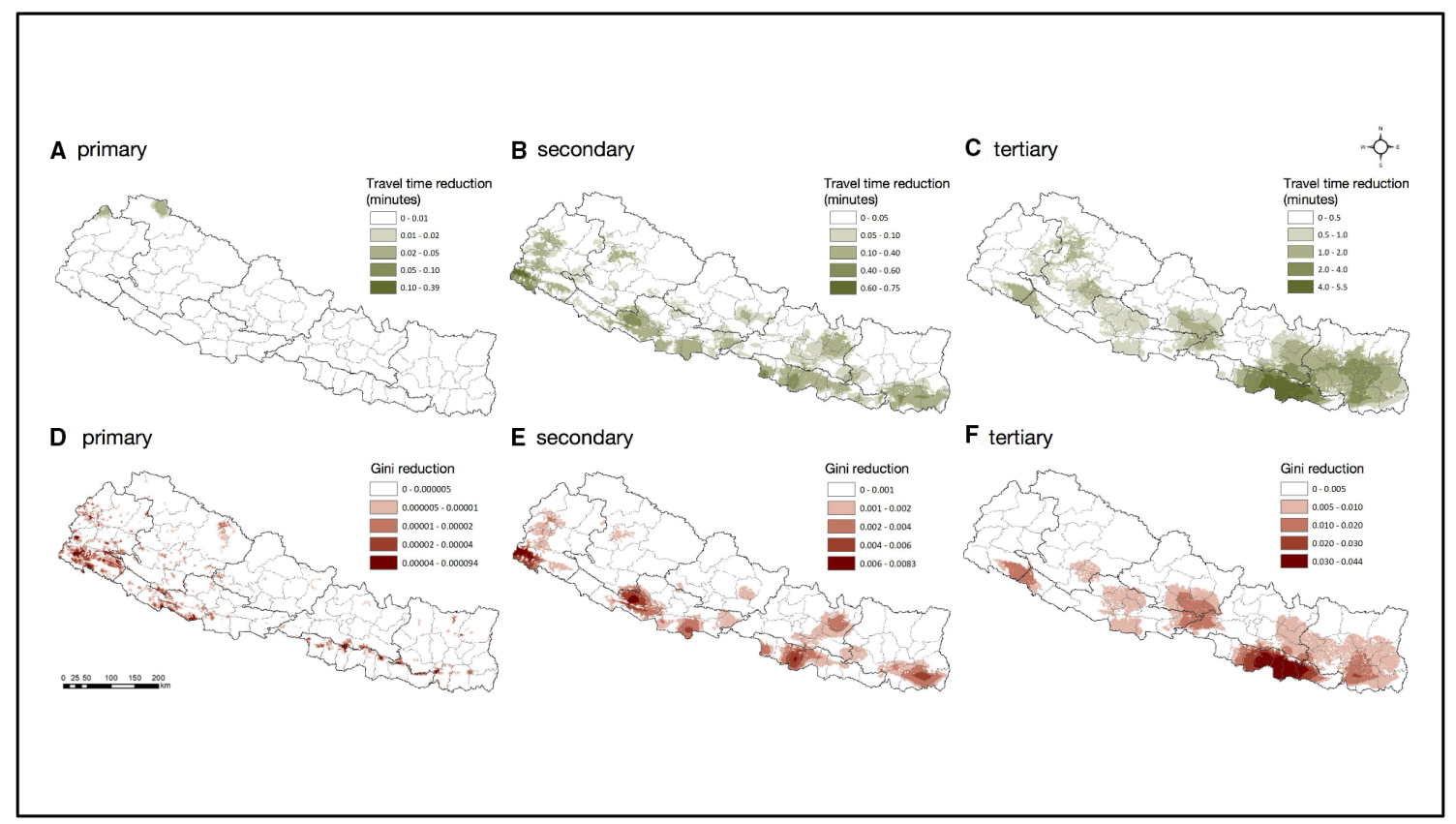

Figure 3 Reductions of travel time and Gini coefficient for new facility placement in Nepal, with motorised mode. 
Overall, geographical accessibility was higher in the central and southern terai areas but lower in the northern mountain areas, due to more health facilities and better road conditions in the former areas. Lower-level health facilities, which were more in quantity and wider distribution, had better accessibility than higher-level ones, as expected. This study provided quantitative results to support the expectations. Besides, even though public health facilities are less accessible in some areas (eg, northern mountain areas), the geographical accessibility of any public health facilities and primary ones was calculated absolutely equal (with Gini< $<.2$ ), as the distribution of population was quite consistent with the distribution of the facilities (online supplemental figures S1 and S2).

It is important to consider equality and efficiency when planning additional public healthcare resource allocation. For primary facilities, we found that the equality of geographical accessibility was good, thus, the improvement may better focus on increasing the average geographical accessibility. Such accessibility was good in most areas except for the northern mountain belt and some areas of south terai belt. Taken account of both geographical accessibility level and population, under the walking mode, areas in Humla district of province No.6 in the northern part (less populous but with extremely low accessibility) and areas in Kanchanpur district of province No.7 in the southern part (populous and with relatively low accessibility) were identified priority for new primary facilities (online supplemental figure S4). For secondary facilities, geographical accessibility was relatively low in several areas of south terai belt with motorised mode, as areas in Rautahat district was more populous, new resources allocation there could improve both geographical equality and accessibility to a greater extent. Similarly, for tertiary facilities, areas in the central part of province No.2 were the best choice to improve both geographical equality and accessibility at the same time. Of note, the potential locations identified in the study was mainly based on geographical accessibility instead of overall accessibility, and should be treated with caution for new resource allocation.

We divided the travel time into seven ranges based on six common/meaningful cut-off points, with the aim to summarise the population travel time coverages. Particularly, $5 \mathrm{~min}, 15 \mathrm{~min}, 30 \mathrm{~min}$ and $90 \mathrm{~min}$ were common cut-off points adopted by many previous studies for population coverage summary ${ }^{35-38}$; 60 min was considered the golden time for treatment of several important acute diseases, such as traumatic injury ${ }^{39}$; and $120 \mathrm{~min}$ is the definition of the maximum access time for timely essential surgery by the Lancet Commission on Global Surgery. ${ }^{31}$ Besides, the time intervals wouldn't affect any subsequent analyses (ie, measures of inequality, identification of locations for new facility), since they were based on the actual calculated travel time instead of the population travel time coverages.

We found that $79.81 \%$ of population could access primary facilities in $30 \mathrm{~min}$ with walking mode. The result is higher than the findings of the Nepal Living Standards Survey in 2010-2011, showing $61.8 \%$ of households could reach the nearest health posts within $30 \mathrm{~min},{ }^{11}$ indicating that the geographical accessibility to primary health facilities has been improved during the past 10 years. The geographical accessibility and equality of health facilities with motorised mode was much better than that with walking mode, suggesting the importance of motorised transport availability to Nepalese. As a large proportion of households $(89.74 \%)$ did not own automated vehicles ${ }^{18}$ the public transport and walking became the major travel modes available for people seeking healthcare. ${ }^{10} 14$ However, the public transport system in Nepal was poor, ${ }^{40}$ urging the government to increase the investment and to improve the management for a higher efficiency system, and increase public transit routes connecting health facilities and major residential places, benefit for more people. On the other hand, even with motorised mode, people living in mountain belt and western hill belt were still poorly accessible to health facilities. Besides, the road network in Nepal was affected greatly by seasons and monsoon. ${ }^{41}$ Thus, the enhancement of transportation network construction was necessary. ${ }^{42}$ Construction of high-quality roads or other practical transportation infrastructure may be priority for populous hill areas to minimise the seasonal influence. And for the northern mountain belt with extremely transport-adverse topography and less populous, ${ }^{41}$ the establishment of integrated settlements with health facilities could be more effective. $^{43}$

We found that the geographical accessibility and its equality decreased with the increase of levels of public health facilities, and primary facilities showed relatively good geographical accessibility in most populated areas and distributed quite consistent with population. However, it was not necessarily mean that the overall accessibility to primary facilities were good (see more discussions in the next paragraph). Besides, other issues for primary facilities should not be ignored, such as low quality of healthcare services, less professional staff, poor availability of drugs and equipment and poor capacity for preventing infections. ${ }^{134445}$ Still, the geographical accessibility and the equality of higher level facilities in Nepal should be improved. This study identifies areas with lowest geographical accessibility and provides potential locations where new facilities could be built. However, for resource-limited settings, establishment of higher level health facilities may be unrealistic. ${ }^{46}$ In addition, over $90 \%$ of inequalities for all three levels of health facilities were attributed to differences within provinces. The reasons behind were complex and might explained by a variety of socioeconomic and political factors, such as the limited ability of the health financing system to identify the poor and the irrational allocation of the within-province health budget. ${ }^{847}$ It may require multifaceted considerations to reduce the existing inequalities, from both national and local perspectives. For example, the national government could explicitly 'prioritise vulnerable groups' in 
macropolicy and promote provincial health governance to be more responsive to local needs through implementation of national policies. ${ }^{47} 48$ In addition, it is important to ensure sufficient linkages between the local and national levels in terms of local health planning and budgeting processes. ${ }^{8}$ Besides, between-province inequalities should not be ignored. Between-province inequalities might relate to the subnational variation of national health financing and differences in local financing to healthcare services. ${ }^{47}$ Studies suggested that the national health sector should strengthen the merging of various health funds and set up clear goals and strict implementation plans for budget execution and achievement of results as planned. ${ }^{47} 49$

Frankly, several limitations should be noted in this study. First, this study only focused on geographical accessibility of health facilities in Nepal, but did not take into account other important determinants that could affect people's access to healthcare services, such as socioeconomic status, culture issues, personal preferences, language barriers, opening hours of health facilities. ${ }^{84} 50$ To be noted, the outcomes of this study provided important but not sufficient information for accessibility to healthcare services in Nepal. After all, the geographical accessibility is one important aspect of the overall accessibility, but not equivalent to the latter. Plans for health resource allocation should be made after comprehensive assessment of geographical, social and other determinants influencing the overall accessibility to healthcare services, instead of just based on one single determinant. Second, we measured geographical accessibility by calculating the travel time, without consideration of resources (eg, number of health workers, hospital beds) in each public health facility, due to unavailability of these kinds of data, which may not represent quantitatively the amount of health services accessed. Indeed, the results presented here mainly focus on the travel time that people could geographically reach a nearest public health facility, which is of great importance as well. Third, the travel time was calculated based on the friction surface under stable travel conditions, which did not take into account the seasonal influence on roads, the actual transportation of each individual, people's preference for health facilities or temporal dynamic of health facilities, thus might compromise the representativeness of the accessibility maps for the real situation. Notwithstanding, results calculated under the two travel modes (ie, walking and motorised modes) showed the maximum and the minimum of travel time, the interval of which may cover the time for people with actual travel modes. Fourth, we considered mainly public health facilities instead of non-public facilities in the study, as public ones are the major subject for governmental resource planning, and there are no clear criteria to classify levels of the non-public ones. Nonetheless, we also provide the geographical accessibility maps of overall facilities (including both public and non-public ones) and of nonpublic facilities in online supplemental appendix page
10. The population-weighted average travel time to the nearest any health facility (either public or non-public one) were $17.65 \mathrm{~min}$ and $32.45 \mathrm{~min}$ with the motorised and the walking modes, respectively, which were close to the travel time to the nearest public health ones, suggesting the exclusion of non-public facilities may have little effect on the results. Despite the limitations, the maps highlight areas where geographical accessibility was poor, valuable as a basis for evidence-based medical planning and resource allocation in Nepal.

\section{CONCLUSION}

The high-resolution geographical accessibility maps enable evidence-based assessment of underserved areas. Accessibility with motorised transport mode better than that with walking mode highlights the importance of a more efficiency public transport system and better transportation network. Low accessibility and high disparities of higher level public health facilities urge the government to advance the hierarchical healthcare system. The findings provide valuable information for evidence-based health planning and resource allocation in Nepal.

Acknowledgements We are grateful to Ting-ting Zhao, Chu-chun Wen, Qing Zou, Si-yue Huang, Hai-yan Xiao and Li Wang for facilitating the data collection. This work has also used the dataset of Nepal formal public health facilities from Nepal Health Facility Registry, and we express our thanks to those involved in building the dataset.

Contributors W-RC did the literature review, contributed to study design, data curation, data analysis, visualisation and drafted and revised the manuscript. PS and BK accessed and verified the data, and revised the manuscript. Y-TH and DRX contributed to study design and revised the manuscript. Y-SL contributed to funding acquisition, study design, data curation, data analysis, supervision, visualisation and revised the manuscript. PS, BK, DRX, Y-TH and Y-SL provided important intellectual content. Y-SL is responsible for the overall content as the guarantor. All authors had full access to all the data in the study and had final responsibility for the decision to submit for publication.

Funding This work was supported by the National Natural Science Foundation of China (project no. 82073665) and theChina Medical Board (project no. 17-274).

Competing interests None declared.

Patient consent for publication Not applicable.

Provenance and peer review Not commissioned; externally peer reviewed.

Data availability statement Data are available in a public, open access repository.

Supplemental material This content has been supplied by the author(s). It has not been vetted by BMJ Publishing Group Limited (BMJ) and may not have been peer-reviewed. Any opinions or recommendations discussed are solely those of the author(s) and are not endorsed by BMJ. BMJ disclaims all liability and responsibility arising from any reliance placed on the content. Where the content includes any translated material, BMJ does not warrant the accuracy and reliability of the translations (including but not limited to local regulations, clinical guidelines, terminology, drug names and drug dosages), and is not responsible for any error and/or omissions arising from translation and adaptation or otherwise.

Open access This is an open access article distributed in accordance with the Creative Commons Attribution Non Commercial (CC BY-NC 4.0) license, which permits others to distribute, remix, adapt, build upon this work non-commercially, and license their derivative works on different terms, provided the original work is properly cited, appropriate credit is given, any changes made indicated, and the use is non-commercial. See: http://creativecommons.org/licenses/by-nc/4.0/.

\section{ORCID iD}

Ying-Si Lai http://orcid.org/0000-0003-4324-5465 


\section{REFERENCES}

1 World Health Organization. Universal health coverage. Available: https://www.who.int/health-topics/universal-health-coverage\#tab= tab_1 [Accessed 16th May 2021].

2 Sharma J, Aryal A, Thapa GK. Envisioning a high-quality health system in Nepal: if not now, when? Lancet Glob Health 2018;6:e1146-8.

3 World Health Organization. Nepal - who country cooperation strategy: 2018-2022. New Delhi: WHO Regional Office for SouthEast Asia, 2018.

4 Khanal P, Mishra SR. Federal governance and the undying parade for universal health coverage in Nepal. Health Prospect 2019;18:1-3.

5 Nepal Planning Commission. Nepal millennium development goals progress report 2013. Kathmandu: National Planning Commission, 2013.

6 Ashworth HC, Roux TL, Buggy CJ. Healthcare accessibility in the rural plains (terai) of Nepal: physical factors and associated attitudes of the local population. Int Health 2019;11:528-35.

7 Saito E, Gilmour S, Yoneoka D, et al. Inequality and inequity in healthcare utilization in urban Nepal: a cross-sectional observational study. Health Policy Plan 2016;31:817-24.

8 Ministry of Health and Population, Government of Nepal. Nepal health sector strategy: 2015-2020. Kathmandu: Ministry of Health and Population, Government of Nepal, 2015.

9 Kelly C, Hulme C, Farragher T, et al. Are differences in travel time or distance to healthcare for adults in global North countries associated with an impact on health outcomes? A systematic review. BMJ Open 2016;6:e013059.

10 Bhattarai S, Parajuli SB, Rayamajhi RB, et al. Health seeking behavior and utilization of health care services in eastern hilly region of Nepal. Journal of College of Medical Sciences-Nepal 2015;11:8-16.

11 Central Bureau of Statistics. Nepal living standards survey 2010/11. Kathmandu: Central Bureau of Statistics, 2011.

12 Weiss DJ, Nelson A, Vargas-Ruiz CA, et al. Global maps of travel time to healthcare facilities. Nat Med 2020;26:1835-8.

13 Ministry of Health, Nepal. Nepal health facility survey 2015. Kathmandu: Ministry of Health, Nepal, 2017.

14 van Loenhout JAF, Delbiso TD, Gupta S, et al. Barriers to surgical care in Nepal. BMC Health Serv Res 2017;17:72.

15 Cheng L, Yang M, De Vos J, et al. Examining geographical accessibility to multi-tier hospital care services for the elderly: a focus on spatial equity. J Transp Health 2020;19:100926.

16 Government of Nepal. The constitution of Nepal. Available: https:// www.mohp.gov.np/downloads/Constitution\%20of\%20Nepal\% 202072_full_english.pdf [Accessed 16th May 2021].

17 United Nations Department of Economic and Social Affairs. World population prospects 2019 - population division. Available: https:// population.un.org/wpp/ [Accessed 16th May 2021].

18 Central Bureau of Statistics. National population and housing census 2011. Kathmandu: Central Bureau of Statistics, 2012.

19 Mishra SR, Ghimire S, Shrestha N, et al. Socio-Economic inequalities in hypertension burden and cascade of services: nationwide cross-sectional study in Nepal. J Hum Hypertens 2019;33:613-25

20 Ministry of health and population, government of Nepal. Nepal health facility registry. Nepal health facility registry digital Repository, 2021. Available: https://nhfr.mohp.gov.np/home

21 Health infrastructure information system. Available: http://5.9.167.97/ [Accessed 25th May 2021].

22 WorldPop. Population counts / unconstrained individual countries 2000-2020 UN adjusted (1 km resolution). Worldpop Digital Repository 2020.

23 Weiss DJ, Nelson A, Vargas-Ruiz CA. Walking only friction surface \& motorized friction surface. Malaria Atlas Project, 2020. Available: https://malariaatlas.org/research-project/accessibility-to-healthcare/

24 Dijkstra EW. A note on two problems in connexion with graphs. Numer Math 1959;1:269-71.

25 Nelson A, Weiss DJ, van Etten J, et al. A suite of global accessibility indicators. Sci Data 2019;6:266.

26 Ministry of Urban Development, Government of Nepal. Nepal urban road Standard-2076. Available: https://pusprajbhatt.files.wordpress. com/2020/02/nepal-urban-road-standard-2076.pdf [Accessed 31th Aug 2021].
27 Ministry of Federal Affairs and Local Development, Government of Nepal. Nepal rural road standards (2055) 1st revision. Available: http://archive.rapnepal.com/sites/default/files/report-publication/ nepal_rural_roads_standards_2012-final_0.pdf [Accessed 31th Aug 2021].

28 Wagstaff A, Paci P, van Doorslaer E. On the measurement of inequalities in health. Soc Sci Med 1991;33:545-57.

29 Luo W, Qi Y. An enhanced two-step floating catchment area (E2SFCA) method for measuring spatial accessibility to primary care physicians. Health Place 2009;15:1100-7.

30 Kwan M-P. Space-Time and integral measures of individual accessibility: a comparative analysis using a Point-based framework. Geogr Anal 1998;30:191-216.

31 Meara JG, Leather AJM, Hagander L, et al. Global surgery 2030: evidence and solutions for achieving health, welfare, and economic development. The Lancet 2015;386:569-624.

32 Theil $\mathrm{H}$. Economics and information theory. Amsterdam: NorthHolland, 1967.

33 Hulland EN, Wiens KE, Shirude S, et al. Travel time to health facilities in areas of outbreak potential: maps for guiding local preparedness and response. BMC Med 2019;17:232.

34 van Etten J, Etten JV. R Package gdistance : Distances and Routes on Geographical Grids. J Stat Softw 2017;76.

35 Lovett A, Haynes R, Sünnenberg G, et al. Car travel time and accessibility by bus to general practitioner services: a study using patient registers and GIS. Soc Sci Med 2002;55:97-111.

36 Leira EC, Fairchild G, Segre AM, et al. Primary stroke centers should be located using maximal coverage models for optimal access. Stroke 2012;43:2417-22.

37 Visconti RM, Larocca A, Marconi M. Accessibility to First-Mile health services: a time-cost model for rural Uganda. Soc Sci Med 2020;265:113410.

38 Schmitz MM, Serbanescu F, Kamara V, et al. Did saving mothers, giving life expand timely access to lifesaving care in Uganda? A spatial District-Level analysis of travel time to emergency obstetric and newborn care. Glob Health Sci Pract 2019;7:S151-67.

39 Clark DE, Cowley RA. R A Cowley, the "Golden Hour," the "Momentary Pause," and the "Third Space". Am Surg 2017;83:1401-6.

40 Central Bureau of Statistics. Nepal - land transport survey, 2013. Available: https://nada.cbs.gov.np/index.php/catalog/48 [Accessed 16th May 2021].

41 Bhagat SK. Situation of land transportation in Nepal. Tribhuvan University Journal 2017;31:193-206.

42 Devkota B, Dudycha D, Andrey J. Planning for non-motorized travel in rural Nepal: a role for geographic information systems. J Transp Geogr 2012;24:282-91.

43 Hall ML, Lee ACK, Cartwright C, et al. The 2015 Nepal earthquake disaster: lessons learned one year on. Public Health 2017:145:39-44.

44 Shah R. Bypassing birthing centres for child birth: a communitybased study in rural Chitwan Nepal. BMC Health Serv Res 2016;16:597.

45 Karkee R, Lee AH, Binns CW. Bypassing birth centres for childbirth: an analysis of data from a community-based prospective cohort study in Nepal. Health Policy Plan 2015;30:1-7.

46 World Health Organization. Domestic General government health expenditure (GGHE-D) as percentage of general government expenditure (GGE) (\%). Available: https://www.who.int/data/ gho/data/indicators/indicator-details/GHO/domestic-generalgovernment-health-expenditure-(gghe-d)-as-percentage-of-generalgovernment-expenditure-(gge) [Accessed 16th May 2021].

47 Uprety S, Lamichhane B. Health budgeting and financing in Nepal: policy perspectives. Available: https://www.herd.org.np/uploads/ frontend/Publications/PublicationsAttachments1/1480582316Health\%20Budgeting\%20and\%20Financing\%20in\%20Nepal\% 20-\%20Policy\%20Perspectives.pdf [Accessed 31th Aug 2021].

48 Kruk ME, Gage AD, Arsenault C, et al. High-Quality health systems in the sustainable development goals era: time for a revolution. Lancet Glob Health 2018;6:e1196-252.

49 Dulal RK, Magar A, Karki SD, et al. Analysis of health sector budget of Nepal. JNMA J Nepal Med Assoc 2014;52:811-21.

50 Ali PA, Watson R. Language barriers and their impact on provision of care to patients with limited English proficiency: nurses' perspectives. J Clin Nurs 2018;27:e1152-60. 